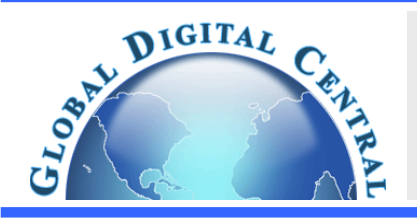

Frontiers in Heat and Mass Transfer

Available at www.ThermalFluidsCentral.org

\title{
SECOND LAW ANALYSIS ON RADIATIVE SLIP FLOW OF NANOFLUID OVER A STRETCHING SHEET IN THE PRESENCE OF LORENTZ FORCE AND HEAT GENERATION/ABSORPTION
}

\author{
M. Govindaraju $\mathrm{u}^{\mathrm{a}}$, B. Ganga ${ }^{\mathrm{b}}$, A.K. Abdul Hakeem ${ }^{\mathrm{a},{ }^{*}}$ \\ a Department of Mathematics,, Sri Ramakrishna Mission Vidyalaya College of Arts and Science, Coimbatore - 641 020, India. \\ ${ }^{\mathrm{b}}$ Department of Mathematics, Providence College for Women, Coonoor - 643 104, India.
}

\begin{abstract}
In this article, we analyzed the second law of thermodynamics applied to an electrically conducting incompressible water based nanofluid flow over a stretching sheet in the presence of thermal radiation and uniform heat generation/absorption both analytically and numerically. The basic boundary layer equations are non-linear PDEs which are converted into non-linear ODEs using scaling transformation. The dimensionless governing equations for this investigation are solved analytically using hypergeometric function and numerically by the fourth order Runge Kutta method with shooting iteration technique. The effects of partial slip parameter with the nanoparticle volume fraction, magnetic parameter, radiation parameter, uniform heat generation/absorption parameter, suction parameter, dimensionless group parameter, Hartmann number and Reynolds number on the entropy generation are discussed for various nanoparticles such as $\mathrm{Cu}, \mathrm{Ag}, \mathrm{Al}_{2} \mathrm{O}_{3}$ and $\mathrm{TiO}_{2}$. It is found that the entropy generation enhances with the increase of magnetic parameter and Hartmann number and decreases with slip parameter.
\end{abstract}

Keywords: Nanofluid, Entropy, Thermal radiation, Heat generation/absorption, Partial slip.

\section{INTRODUCTION}

Thermodynamic irreversibility in any fluid flow process can be quantified through entropy analysis. The first law of thermodynamics is simply an expression of the conservation of energy principle. The second law of thermodynamics states that all real processes are irreversible. Entropy generation is a measure of the account of irreversibility associated with the real processes. Bejans, (1982 and 1996) presented a method named Entropy Generation Minimization (EGM) to measure and optimize the disorder or disorganization generated during a process specifically in the fields of refrigeration (cryogenics), heat transfer, storage and solar thermal power conversion. The shape of nanosize particles on entropy generation is considered by Ellahi et al., 2015. Ellahi, 2015 studied the analytical solutions of shape effects of nanoparticles suspended in HFE-7100 over wedge with entropy generation

Nanofluids are fluids that contain small volumetric quantities of nanometer-sized particles, called nanoparticles. Due to low heat transfer performance of the conventional fluids like water, ethylene glycol, and engine oil in thermal system, obstructs the performance enhancement and the compactness of heat exchangers. The recent nanofluid research shows that nanoparticles change the fluid characteristics because thermal conductivity of these particles is higher than convectional fluids. The broad range of current and future applications involving nanofluids motivated the researchers to find effective techniques for enhancing the heat transfer (Das et al., 2007; Wang and Mujumdar, 2008; Moradi et al., 2015; Akbarzadeh et al., 2016; Sheikholeslami et al., 2015; Sheikholeslami et al., 2015; Noreen et al., 2015; Sheikholeslami et al., 2015).

Hydromagnetic phenomena are outcome of mutual interaction between magnetic field and electrically conducting fluid flowing across it. The behavior of an electrically conducting fluid with electromagnetic field has applications in many different fields of engineering as well as geophysics, astrophysics, technological and industrial manufacturing. This concerns the production of synthetic sheets, aerodynamic extrusion of plastic sheets, cooling of metallic plates, etc. In recent year, several researchers studied the nanofluid boundary layer flow with various physical effects in the presence of magnetic field. (Hamad, 2011; Rashidi et al., 2014; Malvandi et al.,2014; Sheikholeslami et al.,2014; Ellahi et al., 2015; Ellahi et al., 2015; Noreen et al., 2015). When the fluid is particulate such as emulsions, suspensions, foams and polymer solutions, the no-slip condition is inadequate. In such cases, the suitable boundary condition is the partial slip boundary condition (Rashidi et al., 2011; Rashidi et al., 2012). Abdul Hakeem et al., 2014 investigated the partial slip effect on the flow of Newtonian fluid over a stretching sheet. Very recently,

*Corresponding author.Email: abdulhakeem6@gmail.com 
the same author, (2015) studied the second order slip effects on MHD boundary layer flow of nanofluid with thermal radiation effect. The entropy generation analysis has been carried out on the nanofluid flow over stretching surfaces in the following publications without considering the slip effects, (Abolbashari et al., 2014; Govindaraju et al., 2015). The entropy generation on two- phase nanofluid flow has been analyzed by Noghrehabadi, 2013 in the presence of the slip boundary condition.

The aim of the present analysis is to discuss the partial slip effects on entropy generation of magnetohydrodynamic flow of an incompressible viscous nanofluid over a stretching sheet in the presence of thermal radiation and uniform heat generation/absorption both analytically and numerically. The entropy generation is calculated using the entropy relation by substituting the velocity and temperature fields obtained from the momentum and energy equations.

\section{FORMULATION OF THE PROBLEM}

Consider a steady, laminar, two-dimensional radiative slip flow of an incompressible viscous heat generating/absorbing nanofluid over a stretching sheet in the presence of magnetic field. The velocity of the stretching sheet is $\overline{u_{w}}=a \bar{x}$. We also consider influence of a constant magnetic field of strength $B_{0}$, which is applied normally to the sheet. The temperature at the stretching surface takes the constant value $T_{w}$, while the ambient value, attained as $\bar{y}$, tends to infinity and takes the constant value $T_{\infty}$. It is further assumed that the induced magnetic field is negligible in comparison to the applied magnetic field (as the magnetic Reynolds number is small). The fluid is a water based nanofluid containing different types of nanoparticles: copper $(\mathrm{Cu})$, silver $(\mathrm{Ag})$, alumina $\left(\mathrm{Al}_{2} \mathrm{O}_{3}\right)$ and titanium oxide $\left(\mathrm{TiO}_{2}\right)$. It is assumed that the base fluid water and the nanoparticles are in thermal equilibrium and no slip occurs between them. The thermo-physical properties of the nanofluid are considered as in Hamad,2011. Under the above assumptions, the boundary layer equations governing the flow and thermal fields can be written in dimensional form as:

$$
\begin{gathered}
\frac{\partial \bar{u}}{\partial \bar{x}}+\frac{\partial \bar{v}}{\partial \bar{y}}=0 \\
\rho_{n f}\left(\bar{u} \frac{\partial \bar{u}}{\partial \bar{x}}+\bar{v} \frac{\partial \bar{u}}{\partial \bar{y}}\right)=\mu_{n f} \frac{\partial^{2} \bar{u}}{\partial \bar{y}^{2}}-\sigma B_{0}^{2} \bar{u} \\
\left(\rho c_{p}\right)_{n f}\left(\bar{u} \frac{\partial T}{\partial \bar{x}}+\bar{v} \frac{\partial T}{\partial \bar{y}}\right)=k_{n f} \frac{\partial^{2} T}{\partial \bar{y}^{2}}+Q\left(T-T_{\infty}\right)-\frac{\partial q_{r}}{\partial \bar{y}} .
\end{gathered}
$$

Here, $\bar{x}$ and $\bar{y}$ are the coordinates along and perpendicular to the sheet; $\bar{u}$ and $\bar{v}$ are velocity components in $\bar{x}$ and $\bar{y}$ directions, respectively; $T$ is the local temperature of the fluid; $\sigma$ is the electric conductivity; $Q$ is the temperature-dependent volumetric rate of heat source when $Q>0$ and heat sink when $Q<0$ dealing with the situations of exothermic and endothermic chemical reactions respectively and $q_{r}$ is the radiative heat flux.

Using Rosseland approximation for radiation, Abdul Hakeem et al., 2014 we have:

$$
q_{r}=-\frac{4 \sigma^{*}}{3 k_{n f}^{*}} \frac{\partial T^{4}}{\partial \bar{y}} .
$$

Here, $\sigma^{*}$ is the Stefan-Bolltzmann constant and $k_{n f}^{*}$ is the absorption coefficient of the nanofluid. Further, we assume that the temperature difference within the flow is such that $T^{4}$ may be expanded in a Taylor series. Hence, expanding $T^{4}$ about $T_{\infty}$ and neglecting higher order terms, we get:

$$
T^{4} \cong 4 T_{\infty}^{3} T-3 T_{\infty}^{4}
$$

Therefore, Eq.(3) is simplified to:

$\left(\rho c_{p}\right)_{n f}\left(\bar{u} \frac{\partial T}{\partial \bar{x}}+\bar{v} \frac{\partial T}{\partial \bar{y}}\right)=k_{n f} \frac{\partial^{2} T}{\partial \bar{y}^{2}}+Q\left(T-T_{\infty}\right)+\frac{16 \sigma^{*} T_{\infty}^{3}}{3 k_{n f}^{*}} \frac{\partial^{2} T}{\partial \bar{y}^{2}}$.

The effective density of the nanofluid, $\rho_{n f}$, the effective dynamic viscosity of the nanofluid, $\mu_{n f}$, the heat capacitance, $\left(\rho C_{p}\right)_{n f}$, and the thermal conductivity, $k_{n f}$, of the nanofluid are given as:

$$
\begin{gathered}
\rho_{n f}=(1-\phi) \rho_{f}+\phi \rho_{s}, \mu_{n f}=\frac{\mu_{f}}{(1-\phi)^{2.5}}, \\
\left(\rho C_{p}\right)_{n f}=(1-\phi)\left(\rho C_{p}\right)_{f}+\phi\left(\rho C_{p}\right)_{s}, \\
k_{n f}=k_{f}\left(\frac{k_{s}+2 k_{f}-2 \phi\left(k_{f}-k_{s}\right)}{k_{s}+2 k_{f}+\phi\left(k_{f}-k_{s}\right)}\right) .
\end{gathered}
$$

Here, $\phi$ is the solid volume fraction.

The boundary conditions of Eqs.(1)-(3) are:

$$
\begin{array}{ccc}
\bar{u}=a \bar{x}+l \frac{\partial \bar{u}}{\partial \bar{y}}, & \bar{v}=\bar{v}_{w}, \quad T=T_{w} & \text { at } \quad \bar{y}=0 \\
\bar{u} \rightarrow 0, & T \rightarrow T_{\infty} \quad \text { as } & \bar{y} \rightarrow \infty .
\end{array}
$$

where $\mu_{f}$ is the dynamic viscosity of the basic fluid, $\rho_{f}$ and $\rho_{s}$ are the densities of the base fluid and nanoparticle, respectively, $\left(\rho C_{p}\right)_{f}$ and $\left(\rho C_{p}\right)_{s}$ are the specific heat parameters of the base fluid and nanoparticle, respectively, $k_{f}$ and $k_{s}$ are the thermal conductivities of the base fluid and nanoparticle, respectively, and $a$ is constant.

By using the stream function $\psi$, which is defined as $u=\partial \psi / \partial y$ and $v=-\partial \psi / \partial x$ and introducing the following non-dimensional variables:

$x=\frac{\bar{x}}{\sqrt{\nu_{f} / a}}, \quad y=\frac{\bar{y}}{\sqrt{\nu_{f} / a}}, \quad u=\frac{\bar{u}}{\sqrt{a \nu_{f}}}, \quad v=\frac{\bar{v}}{\sqrt{a \nu_{f}}}, \quad \theta=\frac{T-T_{\infty}}{T_{w}-T_{\infty}}$.

Then the equations (2) and (6) become:

$\frac{\partial \psi}{\partial y} \frac{\partial^{2} \psi}{\partial x \partial y}-\frac{\partial \psi}{\partial x} \frac{\partial^{2} \psi}{\partial y^{2}}=\frac{1}{\left(1-\phi+\phi \frac{\rho_{s}}{\rho_{f}}\right)}\left\{\frac{1}{(1-\phi)^{2.5}} \frac{\partial^{3} \psi}{\partial y^{3}}-M n \frac{\partial \psi}{\partial y}\right\}$

$$
\begin{aligned}
\frac{\partial \psi}{\partial y} \frac{\partial \theta}{\partial x}-\frac{\partial \psi}{\partial x} \frac{\partial \theta}{\partial y} & =\left(\frac{3 N r+4}{3 N r}\right) \frac{1}{\operatorname{Pr}} \frac{1}{\left(1-\phi+\phi\left(\rho C_{p}\right)_{s} /\left(\rho C_{p}\right)_{f}\right)} \\
& \times\left(\frac{k_{n f}}{k_{f}}\right) \frac{\partial^{2} \theta}{\partial y^{2}}+\frac{\beta \theta}{\left(1-\phi+\phi\left(\rho C_{p}\right)_{s} /\left(\rho C_{p}\right)_{f}\right)}
\end{aligned}
$$

with the boundary conditions:

$$
\begin{array}{rlrl}
\frac{\partial \psi}{\partial y}=x+L \frac{\partial^{2} \psi}{\partial y^{2}}, & \frac{\partial \psi}{\partial x}=S, & \theta=1 \quad \text { at } \quad y=0 \\
\frac{\partial \psi}{\partial y} \rightarrow 0, & \theta \rightarrow 0 & \text { as } \quad & y \rightarrow \infty .
\end{array}
$$

where $\operatorname{Pr}=\frac{\nu_{f}}{\alpha_{f}}$ is the Prandtl number, $M n=\frac{\sigma B_{0}^{2}}{a \rho_{f}}$ is the magnetic parameter and $\beta=\frac{Q}{a\left(\rho C_{p}\right)_{f}}$ is heat generation/absorption parameter.

Now by using the simplified form of Lie-group transformations namely, the scaling group $\mathrm{G}$ of transformations, Hamad,2011 we get the similarity transformations as:

$$
\eta=y, \quad \psi=x F(\eta), \quad \theta=\theta(\eta) .
$$




\section{SOLUTION OF FLOW FIELD}

Now, using the similarity transformations Eq. (13) in Eq. (10), we get:

$$
F^{\prime \prime \prime}+(1-\phi)^{2.5}\left\{\left[1-\phi+\phi\left(\rho_{s} / \rho_{f}\right)\right]\left(F F^{\prime \prime}-F^{2}\right)-M n F^{\prime}\right\}=0 .
$$

where primes denote the differentiation with respect to $\eta$. The corresponding boundary conditions become:

$$
F(0)=S, \quad F^{\prime}(0)=1+L F^{\prime \prime}(0) \quad \text { and } \quad F^{\prime}(\infty)=0 .
$$

The exact solution to the differential equation (14) satisfying the boundary condition Eq. (15) is obtained as: (see Abdul Hakeem et al., 2014)

$$
F(\eta)=S+X\left(\frac{1-e^{-m \eta}}{m}\right)
$$

where $m$ is the parameter associated with the nanoparticle volume fraction, the magnetic field parameter, slip parameter, suction parameter, the fluid density, and the nanoparticle density as follows:

$$
m=\frac{-0.3333 \frac{\alpha_{1}}{L}-\left(0.4199\left(3 \alpha_{2}-\alpha_{1}^{2}\right)\right)}{L\left(\alpha_{3}+\sqrt{\alpha_{3}^{2}+4 \alpha_{4}^{3}}\right)^{1 / 3}+\delta} .
$$

where:

$$
\begin{aligned}
\delta= & \frac{0.2645 \alpha_{3}+\sqrt{\left(\alpha_{3}^{2}+4 \alpha_{4}^{4}\right)^{1 / 3}}}{L}, \\
\alpha_{1}= & \left\{\rho_{f}-L S(1-\phi)^{2.5} \rho_{f}+L S(1-\phi)^{2.5} \phi \rho_{f}-\right. \\
& \left.L S(1-\phi)^{2.5} \phi \rho_{s}\right\} / \rho_{f}, \\
\alpha_{2}= & \left\{L(1-\phi)^{2.5}\left(-L M n \rho_{f}-S \rho_{f}+S \phi \rho_{f}-S \phi \rho_{s}\right)\right\} / \rho_{f}, \\
\alpha_{3}= & -2+27 L A_{2}+18 L A_{2}-3 S A_{2}+9 M n S L A_{2}^{2}+3 S^{2} A_{2}^{2} \\
& +2 A_{2}^{3} S^{3}-27 L A_{2} \phi+3 S A_{2} \phi-9 L M n S A_{2}^{2} \phi-6 A_{2}^{2} S^{2} \phi \\
& -6 A_{2}^{3} S^{3} \phi+3 A_{2}^{2} S^{2} \phi^{2}+6 A_{2}^{3} S^{3} \phi^{2}-2 A_{2}^{3} S^{3} \phi^{3}+9 L A_{1} \\
& -S A_{1}+3 L A_{1}^{2} M n S+2 A_{2} L A_{1}^{2} S^{2}+2 A_{1}^{3} S^{3}-3 A_{1}^{2} S^{2} \\
& -4 A_{1}^{3} S^{3}+2 A_{1}^{3} S^{3}+A_{1}^{2} S^{2}+2 A_{1}^{3} S^{3}-2 A_{1}^{3}+0.667 A_{1}^{3} S^{3}, \\
& \left\{3 A_{2}\left(-L M n \rho_{f}-S \rho_{f}-S \rho_{f}+S \phi \rho_{s}\right)\right\} / \rho_{f}-\left\{\left(\rho_{f}\right.\right. \\
& \left.\left.-S A_{2} \rho_{f}+A_{2} S \phi \rho_{f}-S A_{2} \phi \rho_{s}\right)^{2}\right\} / \rho_{f}^{2}, \\
\alpha_{4}, & \\
\rho_{f} L(1-\phi)^{2.5} \phi \rho_{s} & A_{2}=L(1-\phi)^{2.5} \text { and } X=\frac{1}{L m+1} .
\end{aligned}
$$

Thus, the non-dimensional velocity components are:

$$
u=x X e^{-m \eta}, \quad v=-\left(S+X\left(\frac{1-e^{-m \eta}}{m}\right)\right) .
$$

The dimensional velocity components are:

$\bar{u}=X a \bar{x} e^{-m \sqrt{a / \nu_{f}} \bar{y}}, \quad \bar{v}=-\left(S+X\left(\frac{1-e^{-m \sqrt{a / \nu_{f}} \bar{y}}}{m}\right)\right) \sqrt{a v_{f}}$.

The shear stress at the stretching sheet characterized by the skin friction coefficient, $C_{f}$, is given by:

$$
C_{f}=\frac{-2 \mu_{n f}}{\rho_{f}\left(\bar{u}_{w}(\bar{x})\right)^{2}}\left(\frac{\partial \bar{u}}{\partial \bar{y}}\right)_{\bar{y}=0} .
$$

Using Eqs. (9), (13), (16) and (19), the skin friction can be written as:

$$
R e_{x}^{1 / 2} C_{f}=-\frac{2}{(1-\phi)^{2.5}} F^{\prime \prime}(0)
$$

where $\operatorname{Re}_{x}=\bar{x} \bar{u}_{w}(\bar{x}) / \nu_{f}$ is the local Reynolds number based on the stretching velocity $\bar{u}_{w}(\bar{x}) . R e_{x}^{1 / 2} C_{f}$ is the local skin friction coefficient.

\section{SOLUTION OF THE THERMAL FIELD}

Substituting the similarity transformations Eq. (13) in Eq. (11), we get:

$$
\begin{array}{r}
\theta^{\prime \prime}+\frac{\operatorname{Pr}_{f}\left[1-\phi+\phi\left(\rho C_{p}\right)_{s} /\left(\rho C_{p}\right)_{f}\right]}{k_{n f}} F \theta^{\prime}\left(\frac{3 N r}{3 N r+4}\right) \\
+\left(\frac{3 N r}{3 N r+4}\right) \frac{P r k_{f}}{k_{n f}} \beta \theta=0 .
\end{array}
$$

and the corresponding boundary conditions are:

$$
\theta(0)=1 \quad \text { and } \quad \theta(\infty)=0
$$

Introducing the new variable:

$$
\xi=-\frac{P r k_{f}\left[1-\phi+\phi\left(\rho C_{p}\right)_{s} /\left(\rho C_{p}\right)_{f}\right]}{m^{2} k_{n f}}\left(\frac{3 N r}{3 N r+4}\right) X e^{-m \eta},
$$

and inserting Eq. (24) in Eq. (22), we obtain:

$$
\xi \theta_{\xi \xi}+\left(1-a_{0}-\xi\right) \theta_{\xi}+\left(\frac{3 N r}{3 N r+4}\right) \frac{P r k_{f}}{k_{n f} m^{2} \xi} \beta \theta(\eta)=0 .
$$

and Eq. (23) transforms to:

$$
\theta\left(-\frac{P r}{\alpha m^{2}}\right)=1 \quad \text { and } \quad \theta(0)=0 .
$$

The solution of Eq. (25) with the corresponding boundary conditions (26), in terms of $\eta$ is written as:

$$
\theta(\eta)=\frac{M\left[\frac{a_{0}+b_{0}}{2}, b_{0}+1,-\frac{P r}{\alpha} \frac{3 N r}{3 N r+4} \frac{X}{m^{2}} e^{-m \eta}\right]}{M\left[\frac{a_{0}+b_{0}}{2}, b_{0}+1,-\frac{P r}{\alpha} \frac{3 N r}{3 N r+4} \frac{X}{m^{2}}\right]} e^{-m \frac{a_{0}+b_{0}}{2} \eta}
$$

where: $M\left[a_{0}, b_{0}+1,-e^{-m \eta}\right]$ is the Kummer's function. which is given as in Abdul Hakeem et al., 2014.

Where

$\alpha=\frac{k_{n f}}{k_{f}\left(1-\phi+\phi \frac{\left(\rho C_{p}\right)_{s}}{\left(\rho C_{p}\right)_{f}}\right)}, \quad a_{0}=\frac{\operatorname{Pr}}{\alpha}\left(\frac{3 N r}{3 N r+4}\right)\left(\frac{S}{m}+\frac{X}{m^{2}}\right)$ and $b_{0}=\sqrt{a_{0}^{2}-\frac{4 \beta P r k_{f}}{m^{2} k_{n f}}\left(\frac{3 N r}{3 N r+4}\right)}$

The Nusselt number, $N u_{x}$, is defined as:

$$
N u_{x}=\frac{\bar{x} \bar{q}_{w}}{k_{f}\left(T_{w}-T_{\infty}\right)}
$$

Where:

$\bar{q}_{w}=-\left(k_{n f}+\frac{16 \sigma T_{\infty}^{3}}{3 k_{n f}^{*}}\right)\left(\frac{\partial T}{\partial \bar{y}}\right)_{\bar{y}=0}$ is the local surface heat flux.

We obtain the following Nusselt number:

$$
R e_{x}^{-1 / 2} N u_{x}=\frac{k_{n f}}{k_{f}}\left(\frac{3 N r+4}{3 N r}\right)\left[-\theta^{\prime}(0)\right]
$$

Where:

$$
\begin{aligned}
\theta^{\prime}(0) & =-m \frac{a_{0}+b_{0}}{2}+\frac{a_{0}+b_{0}}{2\left(1+b_{0}\right)} \frac{3 N r}{3 N r+4} \frac{X P r}{m \alpha} \\
& \times \frac{M\left[\frac{a_{0}+b_{0}}{2}+1, b_{0}+2,-\frac{P r}{\alpha m^{2}} \frac{3 N r}{3 N r+4} X\right]}{M\left[\frac{a_{0}+b_{0}}{2}, b_{0}+1,-\frac{P r}{\alpha m^{2}} \frac{3 N r}{3 N r+4} X\right]} .
\end{aligned}
$$




\section{NUMERICAL METHOD FOR SOLUTION}

The non-linear differential Eqs. (14) and (22) along with the boundary conditions Eq. (15) and Eq. (23) form a two point boundary value problem and are solved using shooting technique together with the fourth order Runge-Kutta integration scheme by converting it into an initial value problem. In this method we have to choose a suitable finite value of $\eta \rightarrow \infty$, say $\eta_{\infty}$. We set following first order system:

$$
\begin{gathered}
F^{\prime}=p, \quad p^{\prime}=q, \\
q^{\prime}=-(1-\phi)^{2.5}\left[\left[1-\phi+\phi\left(\frac{\rho_{s}}{\rho_{f}}\right)\right]\left(F q-p^{2}\right)-M_{n} p\right], \\
\theta^{\prime}=z, \\
z^{\prime}=-\frac{P r k_{f}\left[1-\phi+\phi\left(\rho C_{p}\right)_{s} /\left(\rho C_{p}\right)_{f}\right]}{k_{n f}} \frac{3 N r}{3 N r+4} F z \\
-\frac{3 N_{r}}{3 N_{r}+4} \frac{P r k_{f}}{k_{n f}} \beta \theta .
\end{gathered}
$$

with the boundary conditions:

$$
F(0)=0, \quad p(0)=1+q(0) \text { and } \quad \theta(0)=1 .
$$

To solve Eq. (29) with Eq.(30) as an initial value problem, we must need the values for $q(0)$ i.e. $F^{\prime \prime}(0)$ and $z(0)$ i.e. $\theta^{\prime}(0)$ but no such values are given. The initial guess values for $F^{\prime \prime}(0)$ and $\theta^{\prime}(0)$ are chosen and the fourth order Runge-Kutta integration scheme is applied to obtain the solution. Then we compare the calculated values of $F^{\prime}(\eta)$ and $\theta(\eta)$ at $\eta_{\infty}$ with the given boundary conditions $F^{\prime}\left(\eta_{\infty}\right)=0$ and $\theta\left(\eta_{\infty}\right)=0$, and adjust the values of $F^{\prime \prime}(0)$ and $\theta^{\prime}(0)$ using shooting technique to give better approximation for the solution. The process is repeated until we get the results correct up to the desired accuracy of $10^{-9}$ level, which fulfills the convergence criterion.

\section{ENTROPY GENERATION ANALYSIS}

The local volumetric rate of entropy generation in the presence of magnetic field and thermal radiation can be expressed as: (Woods, 1975 and Arpaci, 1987)

$$
\begin{array}{r}
S_{G}=\frac{k_{n f}}{T_{\infty}^{2}}\left[\left(\frac{\partial T}{\partial \bar{x}}\right)^{2}+\left(1+\frac{16 \sigma^{*} T_{\infty}^{3}}{3 k_{n f}^{*} k_{n f}}\right)\left(\frac{\partial T}{\partial \bar{y}}\right)^{2}\right] \\
+\frac{\mu_{n f}}{T_{\infty}}\left(\frac{\partial \bar{u}}{\partial \bar{y}}\right)^{2}+\frac{\sigma B_{0}^{2}}{T_{\infty}} \bar{u}^{2} .
\end{array}
$$

The contributions of three sources of entropy generation are considered in Eq. (31). The first term indicates the entropy generation due to heat transfer across a finite temperature difference, the second term represents the local entropy generation due to viscous dissipation and the third term indicates the local entropy generation due to the effect of the magnetic field. A dimensionless number for entropy generation rate $N_{S}$ is defined as the ratio of the local volumetric entropy generation rate $\left(S_{G}\right)$ to a characteristic entropy generation rate $\left(S_{G}\right)_{0}$. For a prescribed boundary condition, the characteristic entropy generation rate is:

$$
\left(S_{G}\right)_{0}=\frac{k_{n f}(\Delta T)^{2}}{\bar{x}^{2} T_{\infty}^{2}},
$$

therefore, the entropy generation number is:

$$
N_{s}=\frac{S_{G}}{\left(S_{G}\right)_{0}}
$$

Using Eqs. (27), (31), (32) and (33), the entropy generation number is given by:

$$
N_{s}=\left(\frac{3 N_{r}+4}{3 N_{r}}\right) \theta^{\prime 2}(\eta) R e_{x}+\frac{B r}{\Omega} F^{\prime \prime 2}(\eta) R e_{x}+\frac{B r H a^{2}}{\Omega} F^{\prime 2}(\eta) .
$$

where $\mathrm{Br}$ is the Brinkman number, $\Omega$ is the dimensionless temperature difference and $\mathrm{Ha}$ is the Hartmann number. These number are given by the following relationships:

$$
B r=\frac{\mu_{n f} \bar{u}_{w}^{2}}{k_{n f} \Delta T}, \Omega=\frac{\Delta T}{T_{\infty}}, \quad H a=B_{0} \bar{x} \sqrt{\frac{\sigma}{\mu_{n f}}} .
$$

\section{RESULTS AND DISCUSSION}

In order to gain a clear insight of the physical problem, the results are discussed with the help of graphical illustrations for $A g$-water. The effects of partial slip parameter $(L)$ with magnetic parameter $\left(M_{n}\right)$, radiation parameter $(N r)$, uniform heat generation/absorption $(\beta)$, nanoparticle volume fraction $(\phi)$, suction parameter $(S)$, dimensionless group parameter $\left(B r \Omega^{-1}\right)$, Hartmann number $(H a)$ and Reynolds number $\left(R e_{x}\right)$ on the entropy generation are discussed. The Prandtl number is fixed as 6.2 which is for base fluid water. The values of local skin friction co-efficient and the reduced Nusselt number are tabulated for different nanoparticles such as $\mathrm{Cu}, \mathrm{Ag}, \mathrm{Al}_{2} \mathrm{O}_{3}$ and $\mathrm{TiO}_{2}$. The present results are compared with those of Wang, 1989 and an excellent agreement is observed for a special case which is shown in Table .1 .

Table 1 Comparison of results for the reduced Nusselt number $-\theta^{\prime}(0)$. When $\phi=M n=N r=L=S=\beta=0$.

\begin{tabular}{cccc}
\hline Pr & Present results & & Wang, 1989 \\
\hline \multicolumn{3}{c}{ Analytical } & Numerical \\
0.7 & 0.4539 & 0.4539 & 0.4539 \\
2 & 0.9114 & 0.9114 & 0.9114 \\
7 & 1.8954 & 1.8954 & 1.8954 \\
20 & 3.3539 & 3.3539 & 3.3539 \\
\hline
\end{tabular}

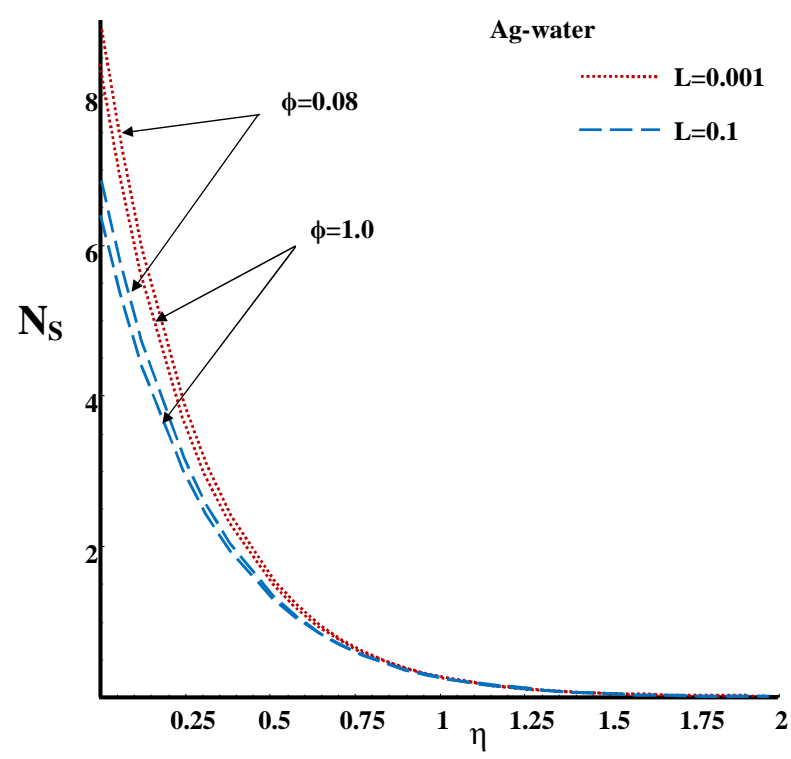

Fig. 1 Effect of nanoparticles volume fraction parameter with partial slip parameter on entropy generation with $\mathrm{Pr}=6.2, \mathrm{Mn}=1.0$, $N r=1.0, S=0.5, B r \Omega^{-1}=1.0, H a=1.0, R e_{x}=1.0$ and $\beta=0.2$.

Fig. 1 shows the combined effect of the nanoparticles volume fraction and partial slip parameter on the entropy generation number. It is found that the entropy generation number decreases with the increasing 
values of nanoparticle volume fraction due to the higher dissipation energy resulted from the sharper velocity gradient near the wall. It is noteworthy that an increase in the slip parameter, the friction between the stretching surface and the nanofluid decreases which ultimately results in less entropy production.

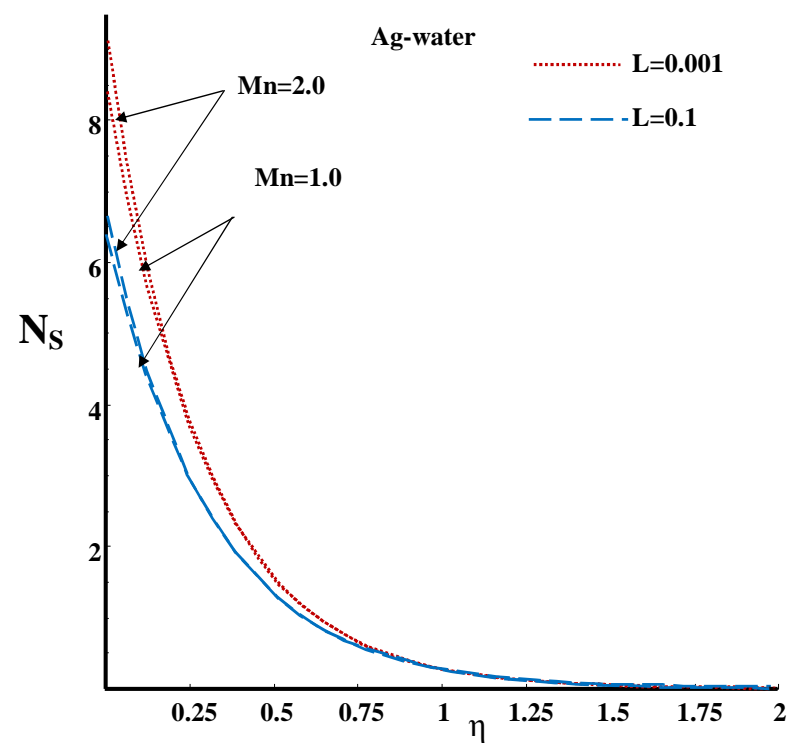

Fig. 2 Effect of magnetic parameter with partial slip parameter on entropy generation with $\mathrm{Pr}=6.2, \phi=0.1, N r=1.0, S=0.5$, $B r \Omega^{-1}=1.0, H a=1.0, \operatorname{Re}_{x}=1.0$ and $\beta=0.2$

The combined effect of magnetic parameter and partial slip parameter on the entropy generation number $\left(N_{s}\right)$ is presented in Fig. 2. This figure shows that the entropy generation increases with magnetic parameter. This happens because the magnetic field supports entropy in the nanofluid. Physically, the presence of the magnetic field creates more entropy generation in the nanofluid as the fluid flow velocity is reduced. The effect of slip parameter reduces the entropy generation in $A g$-water. It is also found that the presence of slip parameter decreases the entropy generation.

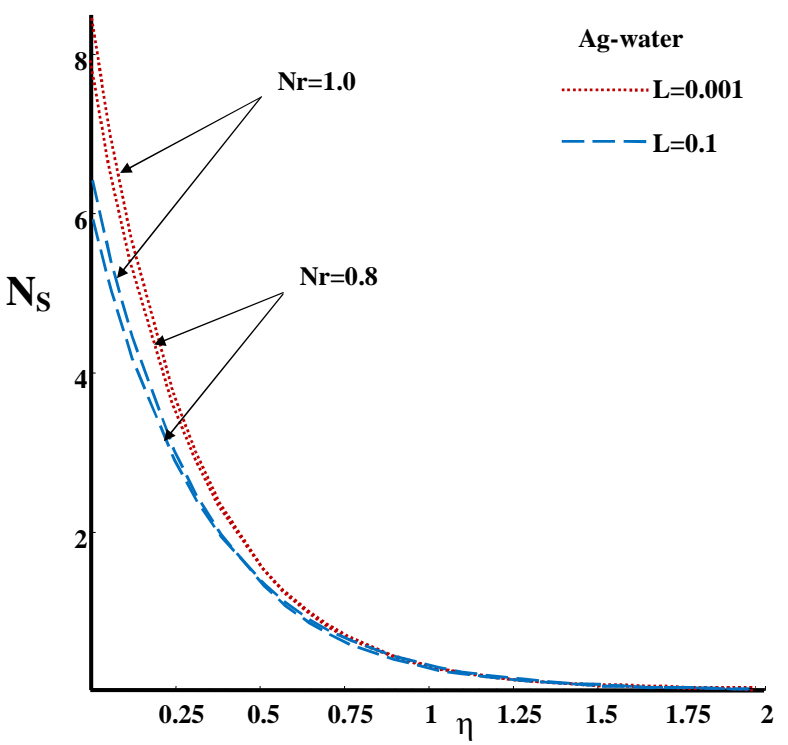

Fig. 3 Effect of radiation parameter with partial slip parameter on entropy generation with $\operatorname{Pr}=6.2, \phi=0.1, M n=1.0, S=0.5$, $B r \Omega^{-1}=1.0, H a=1.0, \operatorname{Re}_{x}=1.0$ and $\beta=0.2$
Fig. 3 demonstrates the combined effect of radiation parameter and partial slip parameter on the entropy generation number. It is observed that the entropy generation increases with the increasing values of radiation parameter near the wall and decreases far away from the wall. An increase in entropy generation is due to the increase of the emission rate of radiation. The combined effect of radiation and slip parameters controls the entropy generation number in $A g$-water.

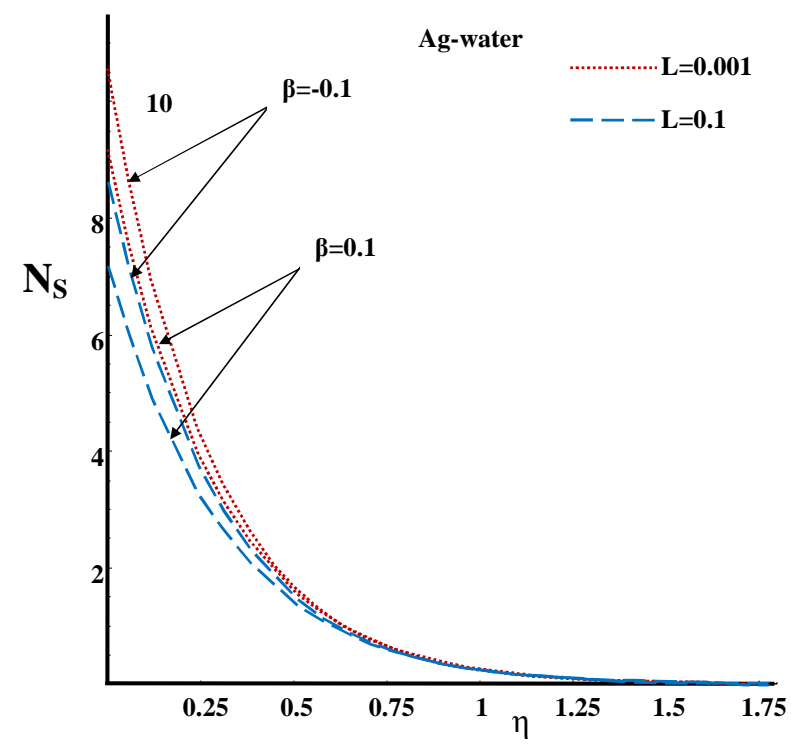

Fig. 4 Effect of uniform heat source/sink parameter with partial slip parameter on entropy generation with $\operatorname{Pr}=6.2, \phi=0.1$, $N r=1.0, S=0.5, B r \Omega^{-1}=1.0, H a=1.0, R_{x}=1.0$ and $M n=1.0$

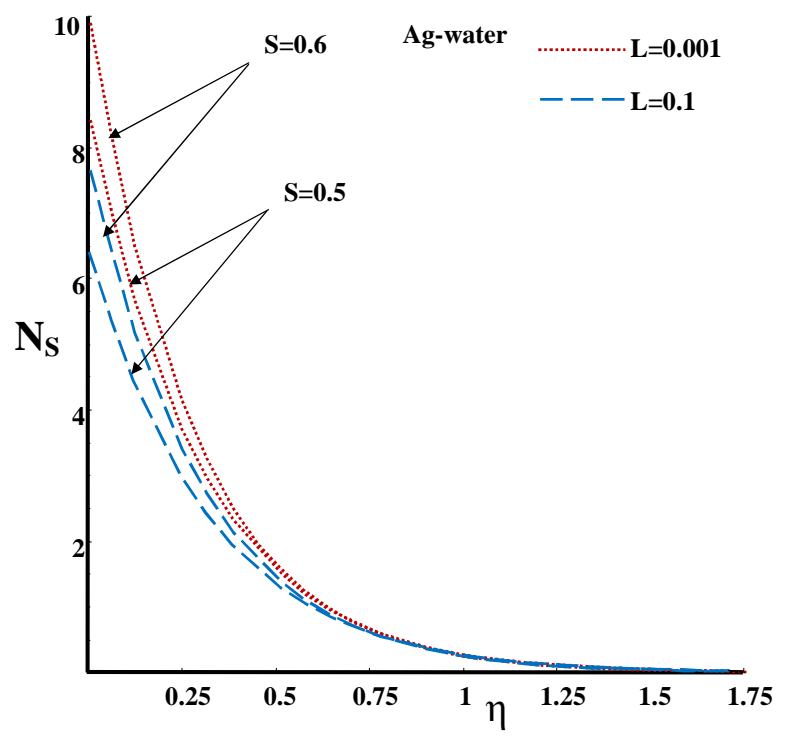

Fig. 5 Effect of suction parameter with partial slip parameter on entropy generation with $\operatorname{Pr}=6.2, \phi=0.1, N r=1.0, \mathrm{Mn}=1.0$, $B r \Omega^{-1}=1.0, H a=1.0, \operatorname{Re}_{x}=1.0$ and $\beta=0.2$

The combined effect of uniform heat generation/absorption parameter and partial slip parameter on the entropy generation number is displayed in Fig. 4. It is clear that the effect of heat generation $(\beta>0)$ in the boundary layer generates the energy which causes the entropy generation to decrease, while the presence of the heat absorption $(\beta<0)$ in the boundary layer absorbs the energy which causes the entropy generation 


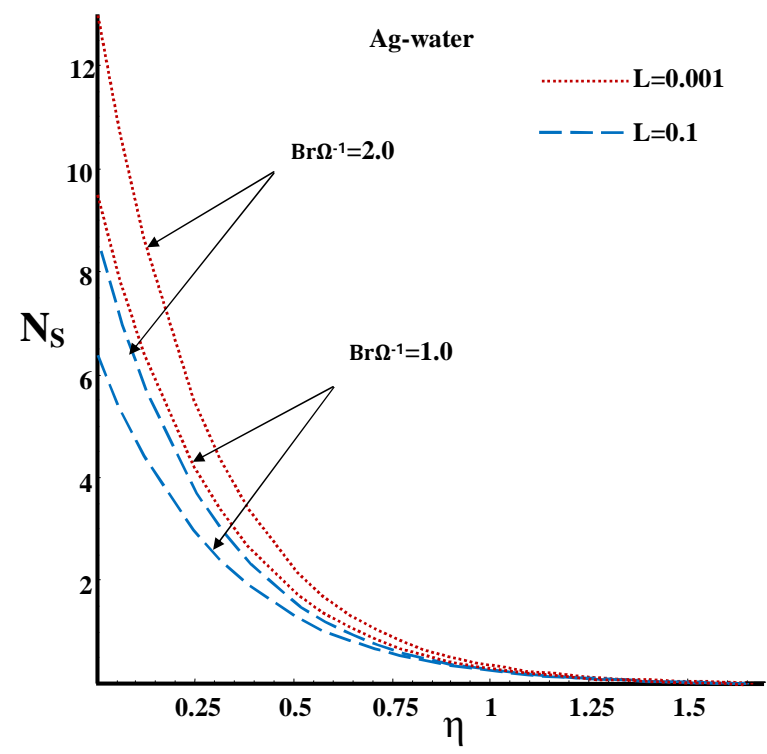

Fig. 6 Effect of dimensionless group parameter with partial slip parameter on entropy generation with $\operatorname{Pr}=6.2, \phi=0.1, \mathrm{Nr}=1.0$, $S=0.5, M n=1.0, H a=1.0, R_{e}=1.0$ and $\beta=0.2$

Table 2 Values of $-F^{\prime \prime}(0)$ for various parameters.

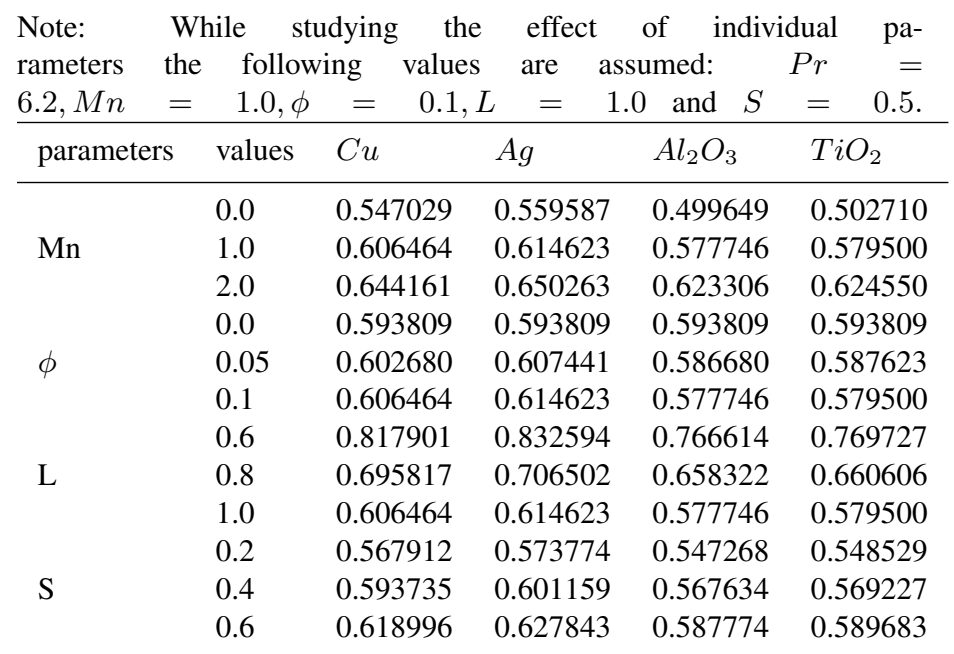

to increase. The combined effect of uniform heat generation/absorption parameter with slip parameter decreases the entropy generation.

Fig. 5 illustrates the combined effect of suction parameter and partial slip parameter on the entropy generation. It is observed that the entropy generation increases with suction parameter. The presence of suction parameter creates more entropy in nanofluid flow region. It is important to note that the surface acts as a strong source of irreversibility. Fig. 6 shows the effect of dimensionless group parameter with partial slip parameter on the entropy generation number. It is observed that the entropy generation augments with the increase of dimensionless group parameter. This is because, the higher values of the dimensionless group parameter increase the nanofluid friction. The combined effect of suction parameter and dimensionless group parameter with slip parameter reduces the entropy generation in $\mathrm{Ag}$-water flow region.

The combined effect of Hartmann number and partial slip parameter on the entropy generation is depicted in Fig. 7. It is seen that the entropy generation number enhances with the increase of Hartmann number. This is due to the fact that an increase in Hartmann number raises the Lorentz forces which strengthen the dissipation energy as a source of irreversibil-

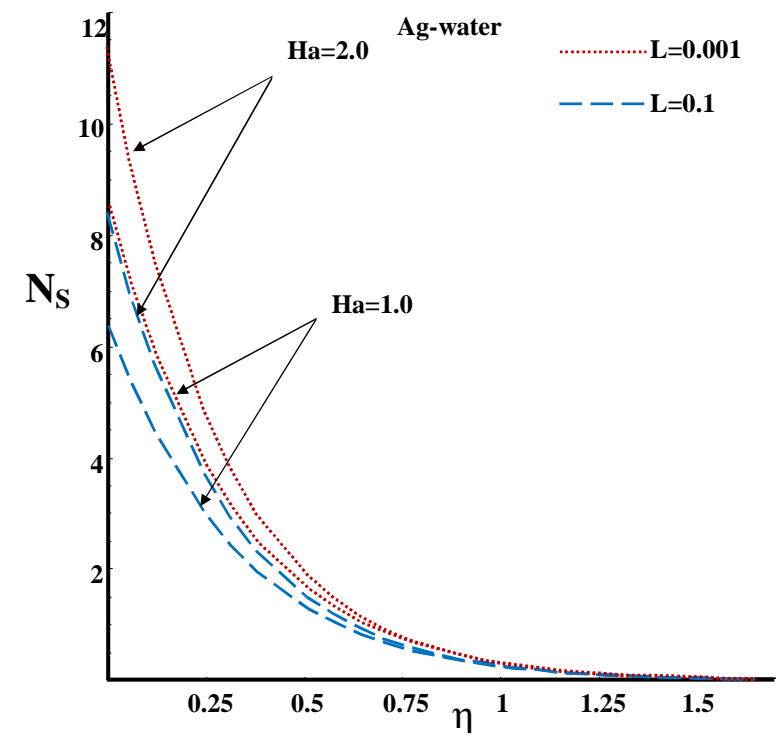

Fig. 7 Effect of dimensionless group parameter with partial slip parameter on entropy generation with $\mathrm{Pr}=6.2, \phi=0.1, \mathrm{Nr}=1.0$, $S=0.5, M n=1.0, H a=1.0, R_{x}=1.0$ and $\beta=0.2$

ity. The entropy generation is presented for different values of Reynolds number and partial slip parameter in Fig. 8. The increasing values of the Reynolds number increase the entropy generation. The enhance value of Reynolds numbers fluid friction increasing the contribution of the entropy generation number as the fluid becomes more viscous. The combined effect of slip parameter with all other parameters leads to diminish the entropy generation in the nanofluid flow region.

The values of local skin friction coefficient and the reduced Nusselt number for different nanoparticles such as $\mathrm{Cu}, \mathrm{Ag}, \mathrm{Al}_{2} \mathrm{O}_{3}$ and $\mathrm{TiO}_{2}$ are tabulated in Table. 2 and Table. 3. On observation of these Tables, it reveal that the skin friction increases with $M n$ and $S$ and decreases with $L$. It is also observed that the increasing values of $\phi$ increase the skin friction coefficient of metallic nanofluids ( $\mathrm{Ag}$-water and $\mathrm{Cu} u$-water) and it has an opposite effect on non-metallic nanofluids $\left(\mathrm{Al}_{2} \mathrm{O}_{3}\right.$-water and $\mathrm{TiO}_{2}$-water). The reduced Nusselt number increases with $\mathrm{Nr}$ and $\mathrm{S}$ and decreases with $M n, \phi, \beta$ and $L$. It is found that the reduced Nusselt number of non-metallic nanofluids is higher than metallic nanofluids.

\section{CONCLUSION}

An analysis has been carried out to study the entropy generation of hydromagnetic slip flow of an incompressible viscous nanofluid ( $\mathrm{Cu}$-water, $\mathrm{Ag}$-water, $\mathrm{Al}_{2} \mathrm{O}_{3}$-water and $\mathrm{TiO}_{2}$-water) over a stretching sheet in the presence of thermal radiation and uniform heat generation/absorption. The entropy generation is calculated using the entropy relation by substituting the velocity and temperature fields obtained from the momentum and energy equations. The main conclusions derived from this study are as follows.

- The increasing values of magnetic field, radiation parameter, suction parameter, heat absorption parameter, Hartmann number, dimensionless group parameter and Reynolds number are lead to enhance the entropy generation in the nanofluid flow field.

- The presence of uniform heat generation diminishes the entropy generation.

- The increase of nanoparticle volume fraction parameter decreases the entropy generation near the wall and increases far away from the wall. 


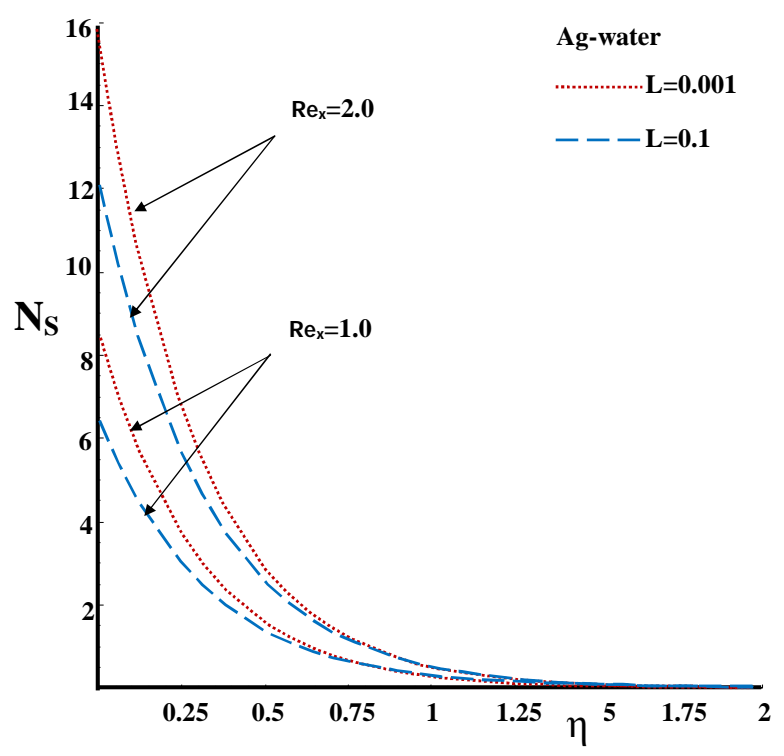

Fig. 8 Effect of Hartmann number with partial slip parameter on entropy generation with $\operatorname{Pr}=6.2, \phi=0.1, N r=1.0, S=0.5$, $B r \Omega^{-1}=1.0, M n=1.0, \operatorname{Re}_{x}=1.0$ and $\beta=0.2$

- The presence of slip parameter reduces the entropy generation in the nanofluid flow region.

- The reduced Nusselt number of non-metallic nanoparticles $\left(\mathrm{Al}_{2} \mathrm{O}_{3}\right.$ and $\left.\mathrm{TiO}_{2}\right)$ is higher than the metallic nanoparticles $(\mathrm{Cu}$ and $\mathrm{Ag})$.

\section{REFERENCES}

Bejan,A., 1982, "Second-Law Analysis in Heat Transfer and Thermal Design", Advances in Heat Transfer, 15, 1-58.

http://dx.doi.org/10.1016/S0065-2717(08)70172-2

Bejan,A., 1996, "Entropy Generation Minimization", CRC Press, Boca Raton, New York.

Ellahi, R., Hassan, M., and Zeeshan, A., 2015, "Shape Effects of Nanosize Particles in $\mathrm{Cu}-\mathrm{H}_{2} \mathrm{O}$ Nanofluid on Entropy Generation", International Journal of Heat and Mass Transfer, 81, 449-456.

http://dx.doi.org/10.1016/j.ijheatmasstransfer.2014.10.041

Ellahi, R., Hassan, M., Zeeshan, A., and Khan Ambreen, A., 2016, “ The Shape Effects of Nanoparticles Suspended in HFE-7100 Over Wedge with Entropy Generation and Mixed Convection ", Applied Nanoscience, 6, 641-651.

http://dx.doi.org/10.1007/s13204-015-0481-z

Das,S.K., Choi, S.U.S., Li, S., Yu , T. W. Pradeep., 2007, "Nanofluids: Science and Technology," Wiley, New Jersey.

Wang,X.Q., Mujumdar, A.S., 2008 "A review of nano fluids - Part 1; Theoretical and Numerical Investigations", Brazilian Journal of Chemical Engineering, 25, 613-630.

Wang, X.Q., Mujumdar, A. S., 2008, "A Review of Nanofluids - Part 2; Experiments and Applications", Brazilian Journal of Chemical Engineering, 25, 631-648.

http://dx.doi.org/10.1590/S0104-66322008000400002 .

Moradi, H., Bazooyar, B., Moheb, A., Etemad, S. G., 2015, “Optimization of Natural Convection Heat Transfer of Newtonian Nanofluids in a
Table 3 Values of $-\theta^{\prime}(0)$ for various parameters.

Note: While studying the effect of individual parameters the following values are assumed: $\operatorname{Pr}=6.2, \mathrm{Mn}=1.0, \phi=$ $0.1, N r=1.0, \beta=0.1, L=1.0$, and $S=0.5$.

\begin{tabular}{llllll}
\hline parameters & values & $\mathrm{Cu}$ & $\mathrm{Ag}$ & $\mathrm{Al}_{2} \mathrm{O}_{3}$ & $\mathrm{TiO}$ \\
\hline \multirow{3}{*}{$\mathrm{Mn}$} & 0.0 & 1.186918 & 1.138235 & 1.251859 & 1.288471 \\
& 1.0 & 1.100849 & 1.057312 & 1.142940 & 1.180682 \\
& 2.0 & 1.044415 & 1.003373 & 1.075436 & 1.113627 \\
$\phi$ & 0.0 & 1.519760 & 1.519760 & 1.519760 & 1.519760 \\
& 0.05 & 1.289757 & 1.265367 & 1.313915 & 1.336101 \\
& 0.1 & 1.100849 & 1.057312 & 1.142940 & 1.180682 \\
$\mathrm{Nr}$ & 0.5 & 0.670633 & 0.634382 & 0.711705 & 0.736774 \\
& 1.0 & 1.100849 & 1.057312 & 1.142940 & 1.180682 \\
& 2.0 & 1.546829 & 1.493839 & 1.590697 & 1.642363 \\
$\beta$ & 0.0 & 1.249262 & 1.213111 & 1.283172 & 1.321955 \\
& 0.1 & 1.100849 & 1.057312 & 1.142940 & 1.180682 \\
& 0.2 & 0.899088 & 0.833742 & 0.962755 & 1.000716 \\
$\mathrm{~L}$ & 0.6 & 1.176621 & 1.132059 & 1.221414 & 1.260182 \\
& 0.8 & 1.134587 & 1.090561 & 1.178106 & 1.216281 \\
& 1.0 & 1.100849 & 1.057312 & 1.142940 & 1.180682 \\
$\mathrm{~S}$ & 0.2 & 0.538900 & 0.491790 & 0.595825 & 0.616188 \\
& 0.4 & 0.917746 & 0.876202 & 0.962075 & 0.993665 \\
& 0.6 & 1.284035 & 1.237746 & 1.324517 & 1.368600 \\
\hline
\end{tabular}

Cylindrical Enclosure", Chinese Journal of Chemical Engineering, 23 (8), 1266 - 1274. http://dx.doi.org/10.1016/j.cjche.2015.04.002 .

Akbarzadeh, M., Rashidi, S., Bovand, R., and Ellahi, R., 2016, “ A Sensitivity Analysis on Thermal and Pumping Power for the Flow of Nanofluid Inside a Wavy Channel", Journal of Molecular Liquids, 220, 1-13. http://dx.doi.org/ 10.1016/j.molliq.2016.04.058 .

Sheikholeslami, M., Davood Domiri Ganjia., Younus Javed, M., and R. Ellahi., 2015, "Effect of Thermal Radiation on Magnetohydrodynamics Nanofluid Flow and Heat Transfer by Means of Two Phase Model", Journal of Magnetism and Magnetic Materials, 374, 36-43.

http://dx.doi.org/ 10.1016/j.jmmm.2014.08.021 .

Sheikholeslami, M., and R. Ellahi., 2015, “ Three Dimensional Mesoscopic Simulation of Magnetic Field Effect on Natural Convection of Nanofluid", International Journal of Heat and Mass Transfer, 89, 799808.

http://dx.doi.org/ 10.1016/j.ijheatmasstransfer.2015.05.110 .

Noreen Sher Akbar., Raza, M.,and Ellahi, R., 2015, “ Influence of Induced Magnetic Field and Heat Flux with the Suspension of Carbon Nanotubes for the Peristaltic Flow in a Permeable Channel ", Journal of Magnetism and Magnetic Materials, 381, 405-415. http://dx.doi.org/ 10.1016/j.jmmm.2014.12.087 .

Sheikholeslami, M., and R. Ellahi., 2015, "Electrohydrodynamic Nanofluid Hydrothermal Treatment in an Enclosure with Sinusoidal Upper Wall", Applied Sciences, 5, 294-306.

http://dx.doi.org/ 10.3390/app5030294

Hamad, M.A.A., 2011, "Analytical Solution of Natural Convection Flow of a Nanofluid Over a Linearly Stretching Sheet in the Presence of Magnetic Field," International Communications in Heat and Mass Transfer, 38, 487-492.

http://dx.doi.org/10.1016/j.icheatmasstransfer.2010.12.042 . 
Rashidi, M. M., Vishnu Ganesh, N., Abdul Hakeem, A.K., Ganga, B., 2014, "Buoyancy Effect on MHD Flow of Nanofluid Over a Stretching Sheet in the Presence of Thermal Radiation", Journal of Molecular Liquids, 198, 234-238.

http://dx.doi.org/10.1016/j.molliq.2014.06.037

Malvandi, A., Ganji, D.D., 2014, "Magnetic Field Effect on Nanoparticles Migration and Heat Transfer of Water/Alumina Nanofluid in a Channel", Journal of Magnetism and Magnetic Materials, 362, 172-179. http://dx.doi.org/10.1016/j.jmmm.2014.03.014.

Sheikholeslami, M., Bandpy, M. G., Ellahi, R., Zeeshan, A.2014, "Simulation of MHD CuO-Water Nanofluid Flow and Convective Heat Transfer Considering Lorentz Forces", Journal of Magnetism and Magnetic Materials, 369, 69-80.

http://dx.doi.org/10.1016/j.jmmm.2014.06.017.

Ellahi, R., Hassan, M., and Zeeshan, A., 2015, “ Study of Natural Convection MHD Nanofluid by Means of Single and Multiwalled Carbon Nanotubes Suspended in a Salt Water Solution", IEEE Transactions on Nanotechnology, 14, 726 - 734.

http://dx.doi.org/10.1109/TNANO.2015.2435899.

Ellahi, R., Hassan, M., and Zeeshan, A., 2015, “ Aggregation Effects on Water Base $\mathrm{Al}_{2} \mathrm{O}_{3}$-Nanofluid Over Permeable Wedge in Mixed Convection", Asia-Pacific Journal of Chemical Engineering , 11, 179-186. http://dx.doi.org/10.1002/apj.1954.

Noreen Sher Akbar., Raza, M., and Ellahi, R., 2015 “ Impulsion of Induced Magnetic Field for Brownian Motion of Nanoparticles in Peristalsis", Applied Nanoscience, 6, 359-370.

http://dx.doi.org/10.1007/s13204-015-0447-1.

Rashidi, M.M., Hayat, T., Erfani, E., Mohimanian Pour, S.A., Awatif AHendi., 2011, "Simultaneous Effects of Partial Slip and Thermal-Diffusion and Diffusion-Thermo on Steady MHD Convective Flow Due to a Rotating Disk", Communications in Nonlinear Science and Numerical Simulation, 16 (11), 4303-4317.

http://dx.doi.org/10.1016/j.cnsns.2011.03.015.

Rashidi, M.M., Erfani, E.,2012, “Analytical Method for Solving Steady MHD Convective and Slip Flow Due to a Rotating Disk with Viscous Dis- sipation and Ohmic Heating", Engineering Computations, 29 (6), 562579.

http://dx.doi.org/10.1108/02644401211246283.

Abdul Hakeem, A. K., Kalaivanan, R., Vishnu Ganesh, N., Ganga, B., 2014, "Effect of Partial Slip on Hydromagnetic Flow Over a Porous Stretching Sheet With Non-uniform Heat Source/Sink, Thermal Radiation and Wall Mass Transfer", Ain Shams Engineering Journal 5, 913-922. http://dx.doi.org/10.1016/j.asej.2014.02.006 .

Abdul Hakeem, A. K., Vishnu Ganesh, N., Ganga, B., 2015, "Magnetic Field Effect on Second Order Slip Flow of Nanofluid Over a Stretching/Shrinking Sheet With Thermal Radiation Effect", Journal of Magnetism and Magnetic Materials, 381, 243-257.

http://dx.doi.org/10.1016/j.jmmm.2014.12.010

Abolbashari, M. H., Freidoonimehr, N., Nazari, F. Rashidi, M. M., 2014, "Entropy Analysis for an Unsteady MHD Flow Past a Stretching Permeable Surface in Nanofluid", Powder Technol. 267, 256-267.

http://dx.doi.org/10.1016/j.powtec.2014.07.028

Govindaraju, M., Vishnu Ganesh, N., Ganga, B., Abdul Hakeem, A.K., 2015, "Entropy Generation Analysis of Magnetohydrodynamic Flow of a Nanofluid Over a Stretching Sheet", Journal of the Egyptian Mathematical Society, 23 (2), 429-434.

http://dx.doi.org/10.1016/j.joems.2014.04.005

Noghrehabadi, A., Saffarian, M. R., Pourrajab, R., Ghalambaz, M., 2013, "Entropy Analysis for Nanofluid Flow Over a Stretching Sheet in the Presence of Heat Generation/Absorption and Partial Slip", Journal of Mechanical Science and Technology. 27, 927-937.

http://dx.doi.org/10.1007/s12206-013-0104-0

Woods, L.C., 1975, "Thermodynamics of fluid Systems", Oxford University Press, Oxford. Arpaci, V. S., 1987, "Radiative Entropy ProductionLost Heat into Entropy", International Journal of Heat and Mass Transfer, 30, 2115-2123.

http://dx.doi.org/10.1016/0017-9310(87)90090-1

Wang, C.Y., 1989, "Free Convection on a Vertical Stretching Surface", Journal of Applied Mathematics and Mechanics (ZAMM), 69, 418-420. http://dx.doi.org/10.1002/zamm.19890691115 